\title{
Establishing the entity of neonatal acute respiratory distress syndrome
}

\author{
Judith Ju-Ming Wong ${ }^{1,2}$, Bin Huey Quek ${ }^{3}$, Jan Hau Lee ${ }^{1,2}$ \\ ${ }^{1}$ Children's Intensive Care Unit, KK Women's and Children's Hospital, Singapore; ${ }^{2}$ Office of Clinical Sciences, Duke-NUS Graduate Medical \\ School, Singapore; ${ }^{3}$ Neonatal Intensive Care Unit, KK Women's and Children's Hospital, Singapore \\ Correspondence to: Jan Hau Lee, MBBS, MRCPCH, MCI. Children's Intensive Care Unit, KK Women's and Children's Hospital, 100 Bukit Timah \\ Road, Singapore 229899. Email: lee.jan.hau@singhealth.com.sg. \\ Provenance: This is an invited Editorial commissioned by Section Editor Dr. Zhiheng Xu (State Key Laboratory of Respiratory Disease, Guangzhou \\ Institute of Respiratory Disease, Department of Intensive Care, The First Affiliated Hospital of Guangzhou Medical University, Guangzhou, China). \\ Comment on: De Luca D, van Kaam AH, Tingay DG, et al. The Montreux definition of neonatal ARDS: biological and clinical background behind \\ the description of a new entity. Lancet Respir Med 2017;5:657-66.
}

Submitted Sep 26, 2017. Accepted for publication Oct 10, 2017.

doi: $10.21037 /$ jtd.2017.10.64

View this article at: http://dx.doi.org/10.21037/jtd.2017.10.64

Contemporary definitions for acute respiratory distress syndrome (ARDS) including the Berlin definition in adults and the Pediatric Acute Lung Injury Consensus Conference (PALICC) definition in children exclude perinatal lung diseases and newborns in general $(1,2)$. This is based on the assumption that newborns frequently develop acute hypoxemic respiratory failure due to conditions such as respiratory distress syndrome (RDS) and transient tachypnea of the newborn which differ patho-physiologically from ARDS. Since the treatment of these perinatal conditions and prognosis differ, it is prudent not to label them as ARDS. However, direct and indirect ARDS do occur in a subset of term and preterm neonates (3). A neonatal ARDS definition is thus justified to increase awareness of a common ARDS spectrum amongst different intensive care disciplines, facilitate research on this condition and the use of specific ARDS therapies for these patients.

De Luca et al. published a position paper with the main purpose of characterizing and defining neonatal ARDS (4). The group reviewed the literature to demonstrate the existence of neonatal ARDS, describe the similarities to pediatric and adult ARDS in biological and pathophysiological aspects and its necessity to guide therapeutic choices. This Montreux definition has similarities with the PALICC definition for pediatric ARDS in that it contains the same 5 criteria: (I) timing of injury; (II) risk factors; (III) lung imaging; (IV) exclusion of a cardiac origin of edema; (V) oxygenation criteria by the oxygenation index (OI).

Unique factors of the Montreux definition are the inclusion of patients from birth to 4 weeks of age or 44 weeks' post-menstrual age regardless of gestational age or birth weight. It includes risk factors such as meconium aspiration syndrome (MAS), congenital pneumonias and perinatal asphyxia which are exclusively diseases of the newborn. RDS and transient tachypnea of the newborn are explicitly excluded, as are congenital malformations that affect the respiratory function. The Montreux definition also takes into account the effects of fetal hemoglobin and transfusion (adult hemoglobin) on the oxygen dissociation curve that may result in unpredictable oxygen saturation and partial pressure of arterial oxygen correlation. As such, the authors have proposed that pulse oximetry readings used to calculate oxygen saturation index or oxygen saturation to fractioned of inspired oxygen $\left(\mathrm{FiO}_{2}\right)$ ratio, not be used to evaluate oxygenation in neonates. As obtaining arterial blood gas might not be possible in all occasions, they have also proposed using transcutaneous arterial oxygen tension in place of arterial values when calculating OI.

The Montreux definition for neonatal ARDS is a step forward in recognizing the existence of ARDS in newborns. The strength of this definition is the detailed consideration of newborn/transition physiology. However, there remains some uncertainty on the applicability of this definition. The 
first issue relates to the impact of arrested lung development in the extreme premature population, the so called "new bronchopulmonary dysplasia (BPD)". Abnormalities of the lung microstructure including reduced and simplified alveolar structures, disrupted alveolar vasculature and fibroproliferation contribute to impaired oxygen diffusion which do not follow the usual trajectory expected in inflammatory ARDS with protein exudation (5).

Secondly, the preterm/newborn lungs are exquisitely susceptible to oxidative stress and any form of mechanical ventilation $(6,7)$. Exposure to high $\mathrm{FiO} 2$ concentration even for short periods can cause epithelial and endothelial necrosis by direct oxidative cell damage through production of reactive oxygen species, accumulation of inflammatory mediators (interleukins (IL)-1, $-6,-8$, transforming growth factor- $\beta$, tumor necrosis factor- $\alpha$ ) and disordered vascular development (mediated by vascular endothelial growth factor and angiopoietins] within the lungs $(6,8,9)$. Expressions of antioxidant enzymes in newborn lungs were demonstrated to be lower than in the developed lungs (7). The effects of mechanical ventilation are illustrated by a study in late-preterm infants showing that a short period (2 hours) of mechanical ventilation was sufficient to cause an imbalance of plasma cytokines (10). Tracheobronchial aspirate fluid in preterm neonates demonstrated increased levels and enhanced mRNA expression of pro-inflammatory cytokines (IL-1, -6, -8, and tumor necrosis factor- $\alpha$ ) and reduced levels of anti-inflammatory cytokines (IL-10, IL-4, IL-12 and IL-13 or IL-1 receptor antagonist) (11-14). These studies also indicated that this pro- and antiinflammatory cytokine imbalance was related to the chronological and gestational age of the infant $(12,13)$. This indicates that meticulous precaution (perhaps more so compared to pediatric/adult ARDS) need to be taken while managing the neonate with ARDS including strict adherence to lung protective ventilation strategies, normoxia and early extubation.

The third consideration is the effect of intrauterine infection or chorioamnionitis on the developing lung. Acute chorioamnionitis can be a clinical diagnosis of maternal fever, elevated white blood cell count, tender uterus, and by amniotic fluid analyses for bacteria or can be a histopathological diagnosis in post-delivery findings of inflammatory cells and necrosis in the placenta (15). Clinicopathological correlation is not always present and the duration of exposure in this case may be unclear $(15,16)$. Some women develop preterm labor and ruptured membranes, but after treatment, delivery may be delayed -these women may carry fetuses with bacterial exposures for days to months obviating the first criteria of the Montreux definition (17). And indeed, some organisms like Ureaplasma partum and Mycoplasma bominies which are normal vaginal flora in women of reproductive age may have prolonged exposures (18). Prolonged Ureaplasma infection in utero in the very preterm infant, together with postnatal consequences of ventilation and oxygen, results in a dysregulated inflammatory response that culminates in the 'new BPD' frequently seen in this population. Management of these infants will be different from other causes of neonatal ARDS.

Fourthly, just as early lung injury due to acute chorioamnionitis may be difficult to differentiate and attributed to RDS until the histopathological examination of the placenta is completed, some congenital/inherited lung disease may also be indistinguishable at the bedside (19). For instance, surfactant protein deficiency syndromes may present initially with RDS but later on, develop a similar recurrent decompensation which is no longer treated as RDS $(20,21)$. Only a lung biopsy will differentiate this from other causes which mimic ARDS. However, the availability of lung biopsy is not widespread. Other conditions like congenital pulmonary lymphangiectasis and alveolar capillary dysplasia may also produce the same conundrum $(22,23)$. Though rare, these entities present in the neonatal period and make the day-to-day diagnosis and management of ARDS challenging.

Lastly, although the Montreux definition advocates measuring pre-ductal partial pressure of oxygen in neonates with persistent pulmonary hypertension and patent ductus arteriosus, the effects of pathophysiological high pulmonary pressures in mal-transitioning newborns may exert complex effects which cannot be simply discounted by measuring the pre-ductal oxygenation. Pulmonary hypertension can occur in infants in 5 settings: (I) abnormally constricted pulmonary vasculature due to pulmonary parenchymal disease (e.g., RDS and MAS); (II) remodeled pulmonary vasculatures in the setting of normal lung parenchyma (e.g., idiopathic persistent pulmonary hypertension of the newborn); (III) structurally hypo plastic pulmonary vasculature (e.g., in lung hypoplasia, congenital diaphragmatic hernia); (IV) hyper viscosity syndromes (e.g., polycythemia) and recently described (V) altered pulmonary vascular growth, remodeling and tone in the new BPD (24-26). The first setting is a relevant consideration, affecting up to $10 \%$ of all causes of respiratory failure in neonates (25). Besides desaturation, pulmonary hypertension is more importantly 
associated with right ventricular dilatation, septal flattening and eventually decreased left ventricular filling and output (25). Of note, traditional classification of severity of pulmonary hypertension utilizes different OI cut-offs (mild $\leq 15$, moderate $\leq 25$, severe $\leq 40$ and very severe $>40$ vs. mild $>4$, moderate $>8$, severe $>16$ in the PALICC definition for PARDS) indicating that the degree of hypoxemia do not commensurate with lung inflammation as for pediatric and adult ARDS (27). This may be attributed in part to rightto-left shunting at the atrial level thus causing desaturation even at pre-ductal regions (28). It is also postulated that intra-pulmonary shunting occur more frequently in neonatal lung disease compared to children/adults and this is evident by the therapeutic efficacy of inhaled nitric oxide in this group $(28,29)$. In addition, the left shift in the oxygen dissociation curve due to properties of the fetal hemoglobin has a significant effect on oxygenation and this too was acknowledged by De Luca and his team (30).

The recognition and development of a neonatal specific definition for ARDS is a commendable effort. However, there remain many challenges in the clinical applicability of this proposed definition. Intuitively, De Luca and his team have initiated a multi-center prospective observational study to determine the practical aspects of applying this definition. Before its use can become routine in clinical practice or research, it is important that this new definition is validated in the appropriate clinical setting across multiple centers and regions. A robust definition of neonatal ARDS should improve the detection of ARDS in infants without causing too much chaos and confusion to the clinician at the bedside.

\section{Acknowledgements}

None.

\section{Footnote}

Conflicts of Interest: The authors have no conflicts of interest to declare.

\section{References}

1. Pediatric Acute Lung Injury Consensus Conference Group. Pediatric acute respiratory distress syndrome: consensus recommendations from the Pediatric Acute Lung Injury Consensus Conference. Pediatr Crit Care Med 2015;16:428-39.
2. ARDS Definition Task Force, Ranieri VM, Rubenfeld GD, et al. Acute respiratory distress syndrome: the Berlin Definition. JAMA 2012;307:2526-33.

3. Pfenninger J, Tschaeppeler H, Wagner BP, et al. The paradox of adult respiratory distress syndrome in neonates. Pediatr Pulmonol 1991;10:18-24.

4. De Luca D, van Kaam AH, Tingay DG, et al. The Montreux definition of neonatal ARDS: biological and clinical background behind the description of a new entity. Lancet Respir Med 2017;5:657-66.

5. Coalson JJ. Pathology of new bronchopulmonary dysplasia. Semin Neonatol 2003;8:73-81.

6. Bhandari V. Hyperoxia-derived lung damage in preterm infants. Semin Fetal Neonatal Med 2010;15:223-9.

7. Berkelhamer SK, Kim GA, Radder JE, Wedgwood S, Czech L, Steinhorn RH, et al. Developmental differences in hyperoxia-induced oxidative stress and cellular responses in the murine lung. Free Radic Biol Med 2013;61:51-60.

8. Pagano A, Barazzone-Argiroffo C. Alveolar cell death in hyperoxia-induced lung injury. Ann N Y Acad Sci 2003;1010:405-16.

9. D'Angio CT, Maniscalco WM. The role of vascular growth factors in hyperoxia-induced injury to the developing lung. Front Biosci 2002;7:d1609-23.

10. Bohrer B, Silveira RC, Neto EC, et al. Mechanical ventilation of newborns infant changes in plasma pro- and anti-inflammatory cytokines. J Pediatr 2010;156:16-9.

11. Baier RJ, Loggins J, Kruger TE. Interleukin-4 and 13 concentrations in infants at risk to develop Bronchopulmonary Dysplasia. BMC Pediatr 2003;3:8.

12. Jones CA, Cayabyab RG, Kwong KY, et al. Undetectable interleukin (IL)-10 and persistent IL-8 expression early in hyaline membrane disease: a possible developmental basis for the predisposition to chronic lung inflammation in preterm newborns. Pediatr Res 1996;39:966-75.

13. Rindfleisch MS, Hasday JD, Taciak V, et al. Potential role of interleukin-1 in the development of bronchopulmonary dysplasia. J Interferon Cytokine Res 1996;16:365-73.

14. Jónsson B, Li YH, Noack G, et al. Downregulatory cytokines in tracheobronchial aspirate fluid from infants with chronic lung disease of prematurity. Acta Paediatr 2000;89:1375-80.

15. Redline RW, Faye-Petersen O, Heller D, et al. Amniotic infection syndrome: nosology and reproducibility of placental reaction patterns. Pediatr Dev Pathol 2003;6:435-48.

16. Jobe AH. Effects of chorioamnionitis on the fetal lung. Clin Perinatol 2012;39:441-57. 
17. Perni SC, Vardhana S, Korneeva I, et al. Mycoplasma hominis and Ureaplasma urealyticum in midtrimester amniotic fluid: association with amniotic fluid cytokine levels and pregnancy outcome. Am J Obstet Gynecol 2004;191:1382-6.

18. Viscardi RM. Ureaplasma species: role in diseases of prematurity. Clin Perinatol 2010;37:393-409.

19. Been JV, Rours IG, Kornelisse RF, et al. Chorioamnionitis alters the response to surfactant in preterm infants. $\mathrm{J}$ Pediatr 2010;156:10-15.e1.

20. Hamvas A. Inherited surfactant protein-B deficiency and surfactant protein-C associated disease: clinical features and evaluation. Seminars in perinatology. Semin Perinatol 2006;30:316-26.

21. Hamvas A. Evaluation and management of inherited disorders of surfactant metabolism. Chin Med J (Engl) 2010;123:2943-7.

22. Hagmann C, Berger TM. Images in clinical medicine. Congenital pulmonary lymphangiectasia. N Engl J Med 2003;349:e21.

23. Tibballs J, Chow CW. Incidence of alveolar capillary dysplasia in severe idiopathic persistent pulmonary hypertension of the newborn. J Paediatr Child Health 2002;38:397-400.

Cite this article as: Wong JJ, Quek BH, Lee JH. Establishing the entity of neonatal acute respiratory distress syndrome. J Thorac Dis 2017;9(11):4244-4247. doi: 10.21037/ jtd.2017.10.64
24. Steinhorn RH. Neonatal pulmonary hypertension. Pediatric critical care medicine 2010;11:S79-S84.

25. Sharma V, Berkelhamer S, Lakshminrusimha S. Persistent pulmonary hypertension of the newborn. Matern Health Neonatol Perinatol 2015;1:14.

26. Alvira CM. Aberrant pulmonary vascular growth and remodeling in bronchopulmonary dysplasia. Front Med (Lausanne) 2016;3:21.

27. Golombek SG, Young JN. Efficacy of inhaled nitric oxide for hypoxic respiratory failure in term and late preterm infants by baseline severity of illness: a pooled analysis of three clinical trials. Clin Ther 2010;32:939-48.

28. Evans N, Kluckow M, Currie A. Range of echocardiographic findings in term neonates with high oxygen requirements. Arch Dis Child Fetal Neonatal Ed 1998;78:F105-11.

29. Krause MF, Lienhart HG, Haberstroh J, et al. Effect of inhaled nitric oxide on intrapulmonary right-to-leftshunting in two rabbit models of saline lavage induced surfactant deficiency and meconium instillation. Eur J Pediatr 1998;157:410-5.

30. Dear PR. Monitoring oxygen in the newborn: saturation or partial pressure? Arch Dis Child 1987;62:879-81. 